\title{
Can interethnic contact between majority (Han) and minority (Uyghur) people in China influence sense of Chinese national Community? The role of positive and negative direct, extended and vicarious intergroup contact
}

\author{
Fei Huang ${ }^{\mathrm{a}, *}$, Kuankuan Shi ${ }^{\mathrm{b}}$, Mingjie Zhou ${ }^{\mathrm{c}}$, Sofia Stathi ${ }^{\mathrm{d}}$, Loris Vezzali ${ }^{\mathrm{e}}$ \\ ${ }^{a}$ School of Psychology, Central China Normal University, PR China \\ ${ }^{\mathrm{b}}$ School of Education, Kashi University, PR China \\ ${ }^{\mathrm{c}}$ Institute of Psychology, Chinese Academy of Sciences, PR China \\ ${ }^{\mathrm{d}}$ School of Human Sciences, University of Greenwich, United Kingdom \\ ${ }^{\mathrm{e}}$ Faculty of Medicine, University of Modena and Reggio Emilia, Italy
}

\section{A R T I C L E I N F O}

\section{Keywords:}

Interethnic contact

Positive contact

Negative contact

Perceived threat

Sense of community

\begin{abstract}
A B S T R A C T
Objectives: In multiethnic countries, enhancing the sense of community and preventing ethnic segregation represents a major challenge. In this study we aimed to test the effects of different forms of intergroup contact in fostering sense of community among majority and minority ethnic groups in China, by focusing on the sense of the community at the national level.

Methods: Participants were Han ( $N=355$, ethnic majority group) and Uyghur ( $N=546$, ethnic minority group) people at a multiethnic university in the Xinjiang province in China.

Results: Results from path analysis revealed that positive direct contact for the minority, and positive extended and vicarious contact for both majority and minority group were indirectly associated with higher sense of Chinese national community via greater focus on positive characteristics of the outgroup. In addition, negative contact (extended contact for the majority; direct contact for the minority) were indirectly associated with lower sense of Chinese national community via reduced focus on positive outgroup characteristics. No evidence was found for negative focus (focus on negative outgroup characteristics) and intergroup threat as mediators. Theoretical and practical implications of the findings for improving intergroup relations in multiethnic and conflictual settings by using multiple forms of intergroup contact are discussed.
\end{abstract}

In the report of the 19th National Congress of Communist Party (CPC) of China held in 2017, the General Secretary of the CPC, Chinese President XI Jinping stated that "We will heighten public awareness of ethnic unity and progress and create a strong sense of community for the Chinese nation. We will encourage more exchanges and interactions among different ethnic groups, helping them remain closely united like the seeds of a pomegranate that stick together, and work jointly for common prosperity and development." This statement points to the importance of creating a community feeling that will allow individuals belonging to different groups to act together as a single community. This statement also suggests that enhancing a community feeling is an important aim that political institutions may be willing to pursue, and therefore investigating how to achieve this can have important real-world implications.

\footnotetext{
* Corresponding author at: School of Psychology, Central China Normal University, NO.152 Luoyu Road, Wuhan, 430079, Hubei, PR China.

E-mail addresses: huangfei@mail.ccnu.edu.cn (F. Huang), 851007099@qq.com (K. Shi), zhoumj@psych.ac.cn (M. Zhou), S.Stathi@gre.ac.uk (S. Stathi), loris.vezzali@unimore.it (L. Vezzali).
} 
From the perspective of intergroup contact theory (Allport, 1954; Pettigrew \& Tropp, 2006) understanding the role of contact in reducing prejudice and improving outgroup attitudes has been widely investigated. If the aim is to understand how to create a more cohesive and peaceful society, there also are other outcomes worth investigating in the context of intergroup contact. Specifically, experiencing a feeling of shared community may deter prejudice and discrimination that ethnic and racial distinctions bring about. This is even more relevant in contexts of intergroup conflict, where prejudice is prevalent. The present research aims to examine whether contact can foster sense of community in a conflictual context largely ignored by contact research, that of the relations between Han (majority) and Uyghur (minority) people in China. Specifically, we focused on the larger community of the China nation, considering the sense of Chinese national community, that we argue may allow the different ethnic communities to coexist in harmony. Importantly, departing from classic contact research, we examined not only direct (face-to-face) contact, but also relevant forms of indirect (not face-to-face) contact, specifically extended and vicarious contact (Dovidio, Eller, \& Hewstone, 2011; Vezzali, Hewstone, Capozza, Giovannini, \& Wölfer, 2014; Wright, Aron, McLaughlin-Volpe, \& Ropp, 1997; Zhou, Page-Gould, Aron, Moyer, \& Hewstone, 2018).

Pettigrew and Hewstone (2017) warned about the risk of omitting critical variables from social-psychological research. Until recently, intergroup contact research, for example, has largely overlooked the role of negative contact, arguably biasing conclusions on the actual role of contact in improving intergroup relations (Graf \& Paolini, 2017). For the first time, we examined simultaneously both positive and negative forms of these direct and indirect types of contact, and we did so by considering both majority and minority group perspectives. Finally, we investigated potential underlying processes of the hypothesized relations.

\section{Sense of community}

Sense of community refers to how people think about the relationship between themselves as individuals and special ingroup memberships that incorporate other group distinctions (Stoeckel, 2016). This variable can be intended as a continuum rather than dichotomic, ranging from low to high level of the construct (Brodsky, 2009). The primary community is the one that provides values, norms, stories, myths and a sense of historical continuity (Sonn \& Fisher, 1998). Among the several definitions of sense of community, the core characteristics include perception of homogeneity and cohesion (Castellini, Colombo, Maffeis, \& Montali, 2011). This definition emphasizes the cognitive component. Following the definition by McMillan and Chavis (1986), Sarason (1974) identified four dimensions of sense of community: membership, influence, integration, and need fulfillment. Based on this model, scales of sense of community were constructed and validated in many populations (e.g., Lardier, Reid, \& Garcia-Reid, 2018; Peterson, Speer, \& McMillan, 2008). This conceptualization (and measurement) taps into the complexity of sense of community, referring to both cognitive and affective components. Because of their multiple group identities, individuals may develop a differentiated sense of community for each identity, even when these are organized in a hierarchical structure (Brodsky \& Marx, 2001; Mannarini, Talò, Mezzi, \& Procentese, 2018).

Sense of community is one of the most widely used and studied constructs in community psychology for it has been found to be positively correlated with several relevant outcomes, such as well-being and community connectedness (Townley, Kloos, Green, \& Franco, 2011). In multiple culture contexts, multiple psychological sense of community is likely to emerge (Brodsky, Loomis, \& Marx, 2002). In a unified multiethnic and collectivistic country such as China, where the study presented in this article was conducted, sense of community can be of great importance and conform to the core value of China. This is especially true for larger communities, such as the whole Chinese nation, as explicitly stated by President XI in an important congress of the Chinese Communist Party. A famous Chinese sociologist, Xiaotong Fei, proposed the concept of "unity in diversity" (where "unity" can be intended with reference to the larger Chinese community) to describe and understand the relationship between individual ethnic groups and Chinese nation as a unity, and the role of the community in the development of positive interethnic relations (Gao, 2019). This idea can be referred to the dialectic of community-diversity (Townley et al., 2011). Because Chinese people's typical thinking style is dialectical, that is it allows to deal with seeming contradictions resulting in a dialectical or a compromise approach (Peng \& Nisbett, 1999), the tension between community and diversity may not be a problem. The compatibility of these two components (Neal \& Neal, 2014) is in fact possible under the institutional effort provided by the Chinese government, shedding light on the importance of building a large human community (Xi, 2018).

In the present study, we are interested in the development of a sense of community that allows to go beyond ethnic divisions. Specifically, we focused on Chinese national community, which includes the different ethnic groups in a larger superordinate group. At the conceptual level, sense of Chinese national community is different from national identity. The main aspect differentiating the two concepts is that the former should be intended within the internal context of a nation, while the latter is more likely to be salient in comparison with other nations.

\section{Intergroup contact and sense of community}

Moving beyond attitudes, Hodson and colleagues proposed an integrative model of intergroup contact that incorporates not only prejudice reduction, but also cognitive outcomes, for example expanding minds and liberalized thinking about the world (Hodson, Crisp, Meleady, \& Earle, 2018).

Sense of community is one of the outcomes that we believe is of major importance to promote positive relations between groups. Indirect evidence for the role of contact in promoting perceptions of shared community is provided by the common ingroup identity model (Gaertner \& Dovidio, 2000). For instance, there is evidence that interethnic contact between school students is associated with greater one-group perceptions (Gaertner, Rust, Dovidio, Bachman, \& Anastasio, 1994; see also Capozza, Trifiletti, Vezzali, \& Favara, 
2013), and this association holds true when conflictual intergroup relations are considered (Stathi, Husnu, \& Pendleton, 2017). Sense of community, however, refers to a broader conceptualization, that has scarcely been explored in the framework of contact theory. For example, among international students studying in other European universities, contact with other EU members was associated to greater sense of the European community (Stoeckel, 2016). A qualitative study found that intergenerational contact reduced agegroup stereotypes and enhanced recognition of intergenerational similarity, resulting in greater sense of community (Alcock, Camic, Barker, Haridi, \& Raven, 2011). Another study found that quantity and quality of contact with immigrants in the neighborhood were significantly correlated with the sense of neighborhood community (Castellini et al., 2011).

In our research, we explore sense of community in a novel context (China) by considering both majority (Han) and minority (Uyghur) members, different types of both positive and negative contact, and potential underlying processes.

\section{Positive and negative intergroup contact}

Allport (1954) proposed that contact would produce beneficial effects for intergroup relations when optimal contact conditions (equal status, cooperation for common goals, institutional support) are present within the contact situation (Pettigrew, 2016). Subsequent research showed that (direct) contact reduces prejudice and that the pre-required conditions posed by Allport can strengthen the effects of contact, but that they are not strictly necessary (Pettigrew \& Tropp, 2006). Recently, attention has been placed on valence of contact rather than on optimal conditions. Specifically, research has started to explore the role of negative as well as of positive contact (e.g., Brylka, Jasinskaja-Lahti, \& Mahonen, 2016; Hayward, Tropp, Hornsey, \& Barlow, 2017; Mahonen \& Jasinskaja-Lathi, 2016; Meleady, Seger, \& Vermue, 2017; Reimer et al., 2017; for a review, see Graf \& Paolini, 2017).

Research conducted in the last 10 years has indicated that negative direct contact is consistently related to increased prejudice (Barlow, Paolini et al., 2012). In addition, its effects on increased prejudice are comparably stronger than the effects of positive contact on reduced prejudice (Paolini, Harwood, \& Rubin, 2010). This may depend at least in part on the likely greater category salience activated by negative contact. In fact, being more consistent with negative expectations and stereotypes about the outgroup, negative contact is more likely to activate the outgroup category, with resulting prominence of negative over positive contact (Graf \& Paolini, 2017). Note, however, that some studies did not reveal prevalence of negative contact, highlighting that positive contact is more common (e.g., Bagci \& Turnuklu, 2019). It is therefore important to conduct additional studies to better understand the interplay between positive and negative direct contact and prejudice or related outcomes. In the present study, given mixed evidence from prior research, we did not advance specific predictions regarding the relative strength of positive and negative direct contact.

Research in the last 20 years also focused on the role of indirect contact in shaping outgroup attitudes. Two especially relevant indirect contact forms are extended and vicarious contact, that is knowing about ingroup members having contact with outgroup members (extended contact) or vicariously observing intergroup contact (vicarious contact) (Vezzali et al., 2014). There is a large body of evidence that both (positive) extended and vicarious contact improve intergroup relations and their effects do not differ between majority and minority groups (for reviews, see Birtel, Vezzali, \& Stathi, 2018; Brown \& Paterson, 2016; Di Bernardo, Vezzali, Stathi, Cadamuro, \& Cortesi, 2017; Turner, Hewstone, Voci, Paolini, \& Christ, 2007; Vezzali et al., 2014; for a meta-analysis on extended contact, see Zhou et al., 2018).

Research taking both positive and negative indirect contact into account is still quite preliminary. Concerning extended contact, there is evidence that both positive and negative contact affect (negatively and positively, respectively) prejudice (Árnadóttir, Lolliot, Brown, \& Hewstone, 2018; Bagci \& Gungor, 2019; Husnu, Mertan, \& Cicek, 2016; Mazziotta, Rohmann, Wright, De Tezanos-Pinto, \& Lutterbach, 2015; Rupar \& Graf, 2019; Vedder, Wenink, \& van Geel, 2017; Visintin, Voci, Pagotto, \& Hewstone, 2017). In a rare test of comparative strength, Wang, Huang, \& Vezzali (2019) tested the effects of both positive and negative extended contact among minority members, and found that positive extended contact had stronger effects on improved outgroup attitudes than negative extended contact on deteriorated outgroup attitudes.

Initial research on vicarious contact has also taken into account both positive and negative contact (Andrews, Yogeeswaran, Walker, \& Hewstone, 2018; Castelli, De Dea, \& Nesdale, 2008). Note that whereas extended contact studies are mainly correlational, vicarious contact studies (including those that consider contact valence) are mainly experimental and often lack ecological validity (cf. Vezzali \& Stathi, 2017). This methodological discrepancy has not yet allowed us to consider these two separate indirect contact forms together. In the present study, we consider simultaneously both extended and vicarious contact, taking into account both their positive and negative forms. However, given the scarcity of research examining the relative contribution of positive and negative extended and vicarious contact, we did not advance specific predictions regarding their comparative strength.

\section{Potential mediators}

Past research has examined whether the focus of the contact experience should be placed on the group or on the individual, hypothesizing that a focus on the group would favor attitude generalization (cf. Brown \& Hewstone, 2005). Contact research (focusing on collective action) has also examined the content of contact, in particular on the effects of considering differences or on commonalities between groups (Saguy \& Chernyak-Hai, 2012; Vezzali, Andrighetto, Capozza, Di Bernardo, \& Saguy, 2017). This research viewed the focus on the group or on the individual, or the focus on differences rather than on commonalities as moderators of contact effects. Adopting a different perspective, Sasaki and Vorauer (2010) argued that, because individuals from both majority and minority groups often have negative intergroup expectancies, focusing on others (rather than on how others perceive them) during interactions should have positive effects on others' perceptions. We argue instead that focusing on others can have both positive and negative consequences on perceptions, and that these consequences will depend on the valence of the characteristics one 
is focusing on. In fact, focusing on positive characteristics should have beneficial effects on improved outgroup attitudes; in contrast, a focus on negative characteristics of others should be associated with more negative outgroup attitudes.

Paolini and McIntyre (2019) conducted a meta-analysis and found that individual-to-group generalization occurs more readily for negative experiences when the outgroup is stigmatized. We aimed to investigate why this generalization may occur. In particular, we examined the role of positive and negative focus during contact. We tested whether positive and negative contact would be associated with greater focus on positive or on negative outgroup characteristics, and how this predicts in turn sense of community. Following results by Paolini and McIntyre (2019), we might speculate that (positive and negative) contact effects will be mediated by both positive focus and negative focus when considering a disliked outgroup: negative interactions with a disliked outgroup should bring attention to negative characteristics, that can in turn relate to decreased sense of Chinese national community, and reduce attention to positive characteristics, which should be in turn associated to greater sense of Chinese national community; in contrast, positive interactions should be associated positively with positive focus and negatively with negative focus.

Another relevant variable that we consider in this research is intergroup threat. Intergroup threat is typically associated with more negative outgroup attitudes (Riek, Mania, \& Gaertner, 2006; Stephan \& Stephan, 2000). It has also been found to be associated negatively with one-group perceptions among majority and minority group members (Andrighetto, Vezzali, Bergamini, Nadi, \& Giovannini, 2016), and is a mediator of both positive (Cakal, Hewstone, Guler, \& Heath, 2016) and negative (Mahonen \& JasinskajaLathi, 2016; see also Aberson, 2019) direct contact effects. In addition, intergroup threat mediates the effects of both positive (Dhont \& Van Hiel, 2011) and negative extended contact (Rupar \& Graf, 2019), among both majority and minority group members (Vedder, Wenink, \& van Geel, 2016).

Based on the literature above, we tested positive and negative focus, as well as intergroup threat as mediators of the path from contact to sense of Chinese national community.

\section{Current study}

According to the 6th nationwide population census of China, the population of Uyghur Chinese is over 10 million, making it the fifth largest ethnic minority in the country. Most of them are resident in Xinjiang Uyghur Autonomous Region, especially concentrated to the south of Tianshan Mountain. However, many Uyghur people also study or work in other provinces around China. Han is China's main ethnic group and Han people reside all around the country. As reported in the Historical Matters Concerning Xinjiang (The State Council Information Office of the People's Republic of China, 2019), Uyghur and Han (the largest two populations), along with 11 other ethnic groups, had settled in Xinjiang by the end of 19th century.

For the people and society in Xinjiang, there are three important and intertwined challenges: separatism, religious extremism, and terrorism, which produce obstacles to interethnic relations. For historical, geopolitical and contemporary reasons, the interethnic contact between Han and Uyghur is to some extent problematic. It is therefore no surprise that it became one of the most investigated interethnic relations in China. The current "Pan-Turkism" and "Pan-Islamism" appeared in Xinjiang at the end of the 20th century, when separatists entered the political scene, promoting beliefs in Islam and the use of the Turkish language in order to establish the theocratic State of "East Turkistan" (The State Council Information Office of the People's Republic of China, 2019). The advocacy of this so-called State has become a political tool and program for separatists and anti-China forces attempting to split China. Most of Han people in Xinjiang neither speak Turkish nor they believe in Islam. So, the three forces in Xinjiang created divisions among the ethnic groups that were present in the area $(\mathrm{Gu}, 2010)$. As a consequence, interethnic relations in the context examined, and especially Han-Uyghur relations, are at best tense. Extreme examples of this conflict are the terrorist attacks that happened in or out of Xinjiang. For example, in recent years, the "7.5" terrorist attack in Urumqi, and the "3.1" terrorist attack in Kunming are two wellknown such events. Not surprisingly, these incidents had a profound and lasting impact on the relationships among the ethnic groups involved. We therefore decided to conduct the study in this context by considering both ethnic majority and minority members, in order to provide a stringent test of our hypotheses and understand the factors that promote a sense of Chinese national community among the two groups.

Although the literature has consistently shown that positive contact improves intergroup relations, little is known about negative contact ('positivity bias'). In addition, despite the fact that intergroup contact is an interactive process, most studies have focused on the perspective of majority groups ('majority bias'). Therefore, we tested the effects of positive and negative contact simultaneously with both majority and minority groups. We also considered sense of Chinese national community as the dependent variable, because we aimed to understand the degree to which contact contributes to creating a more cohesive environment and to helping different ethnic groups to share a sense of the larger (national) community.

To this end, and providing a novel contribution to the contact literature, we consider simultaneously direct, extended, and vicarious contact, taking into account positive and negative valence. Reasoning in terms of perceiving a sense of community, individuals are exposed to a many forms of contact simultaneously. Therefore, considering relevant contact forms can enhance the validity, accuracy and rigor of results (Pettigrew \& Hewstone, 2017). In general terms, we expected that positive contact (either direct, extended, or vicarious) would be associated with greater perceptions of sense of Chinese national community; in contrast, we anticipated negative relationships between negative contact (direct, extended, or vicarious contact) and sense of Chinese national community.

In order to assess the different contact forms, we relied on measures already used in the literature and shown to be predictive in the context examined (direct and extended contact). Given the conceptual similarity between extended and vicarious contact, and because of the absence of a measure of vicarious contact in the examined context, we adapted extended contact items. In order to assess sense of Chinese national community, we used a scale with satisfactory psychometric properties, short, and easy to adapt to the 
specific background of this study, based on one of the most relevant approaches to sense of community (Peterson et al., 2008).

We decided to test positive and negative focus and perceived intergroup threat as potential mediators of the contact effects because we believe they may be especially relevant in the context examined. With respect to positive and negative focus, we argue that the outgroup characteristics that one focuses on, especially in the context of conflictual relations, play a crucial role in the pathway to sense of community. In particular, contact can shape the appraisal of the outgroup and, depending on valence, direct attention to positive or negative characteristics, thereby indirectly contributing to a more positive or negative view of the outgroup and as a consequence to a greater or lower sense of belonging to a single community. Specifically, we hypothesized that positive contact should enhance attention to positive outgroup characteristics (positive focus) and reduce attention to negative outgroup characteristics (negative focus), and in turn foster greater sense of Chinese national community (with positive and negative focus associated with sense of Chinese national community positively and negatively, respectively). We instead hypothesize that negative contact would be associated negatively with positive focus and positively with negative focus, indirectly leading to lower sense of Chinese national community. Given the absence of validated measures, we relied on items developed for the present study.

Intergroup threat may pose an obstacle to perceiving ingroup and outgroup members as part of the same community. In fact, perceiving that the outgroup threatens the ingroup can increase group salience, thereby undermining the salience of the superordinate (in this case, single community) category (Turner, 1999). We therefore argue that intergroup threat is critical to perceived sense of community. In order to assess threat, we relied on a validated measure used in previous studies. In line with literature reported above, we predicted that positive contact should be associated with reduced intergroup threat; intergroup threat should relate to lower sense of Chinese national community, so that contact, by reducing threat, should be indirectly associated with a greater sense of Chinese national community. In contrast, negative contact should be indirectly associated with lower sense of Chinese national community via increased intergroup threat. The model we tested is presented in Fig. 1.

In addition, in line with prior literature, we expected that direct contact will have stronger effects among majority members (Tropp \& Pettigrew, 2005). In fact, majority and minority members rely on different perspectives when approaching intergroup relations, that contribute to determine appraisal of other groups (Shelton, Richeson, \& Vorauer, 2006). Majority members pay typically less attention to differences in status between groups and prefer to perceive ingroup and outgroup as belonging to a common group. In contrast, minority members prefer to recognize status differences and pay more attention to the characteristics that define the groups (Dovidio, Gaertner, \& Saguy, 2009). This leads minority members to be less affected by strategies that reduce perceptions of intergroup differences, such as intergroup contact (Binder et al., 2009). In contrast, the effects of extended and vicarious contact should not differ between groups. Extended and vicarious contact largely operate also through social norms, which define how individuals should perceive reality, and provide indications on whether members of other groups can be considered as belonging to a common group or, in the case of this study, to a community (Vezzali et al., 2014).

Given mixed findings of previous research on direct contact, and scarcity of research on extended and vicarious contact, we do not make specific predictions regarding the strength of the effects of positive vs. negative contact.

\section{Method}

\section{Participants}

Participants were students from a university in Kashi City, located in the southern part of Xinjiang Uyghur Autonomous Region, in northwest China. This city is one of the most western cities in China, sharing borders with some of the central Asian countries, and it has a high population of Uyghur Chinese people. Participants were distributed questionnaires during classes collectively, or outside of class individually by research assistants and teachers. All participants were informed that the study aimed to investigate how Uyghur and Han people interact with each other and to explore their social attitudes. They were briefed about ethics policies regarding anonymity, privacy and data protection. All participants took part in the study voluntarily and anonymously and were informed that they could end their participation at any time. Their participation was rewarded with course credits.

After preliminary checking, we excluded participants with excessive missing variables on the scales used in this research (exceeding $15 \%$ ), yielding a final sample of 355 majority Han Chinese (64\% females, $44 \%$ from provinces outside of Xinjiang) aged between 18 and 24 years $(M=20.23, S D=1.53)$; and 546 minority Uyghur Chinese ( $71 \%$ females, all from Xinjiang) aged between 18 and 26 years $(M=20.96, S D=1.39)$. A minimum sample size of 700 participants (350 for each group) was calculated in order to run a path model with six observed predictors (three exogenous variables and three mediators) allowing a power of .80 to detect a small effect size $\left(f^{2}=.04\right)$.

\section{Measures}

For the ethnic majority Han Chinese people, the outgroup was 'Uyghur Chinese' and the ingroup was 'Han Chinese'; theses labels were inverted for the ethnic minority Uyghur Chinese people. All items are reported in the Appendix A.

\section{Positive and negative contact}

Three types of contact were measured, that is direct, extended, and vicarious contact, with all items adapted from the multidimensional interethnic scale measuring positive and negative contact (Huang, Wang, Shi, \& Halike, 2018).

Each subscale was composed of four items. Positive and negative direct contact items had been used in the Han-Uyghur interethnic context by Wang, Huang, Stathi, \& Vezzali (2020). Positive and negative extended contact had been used in the interethnic 

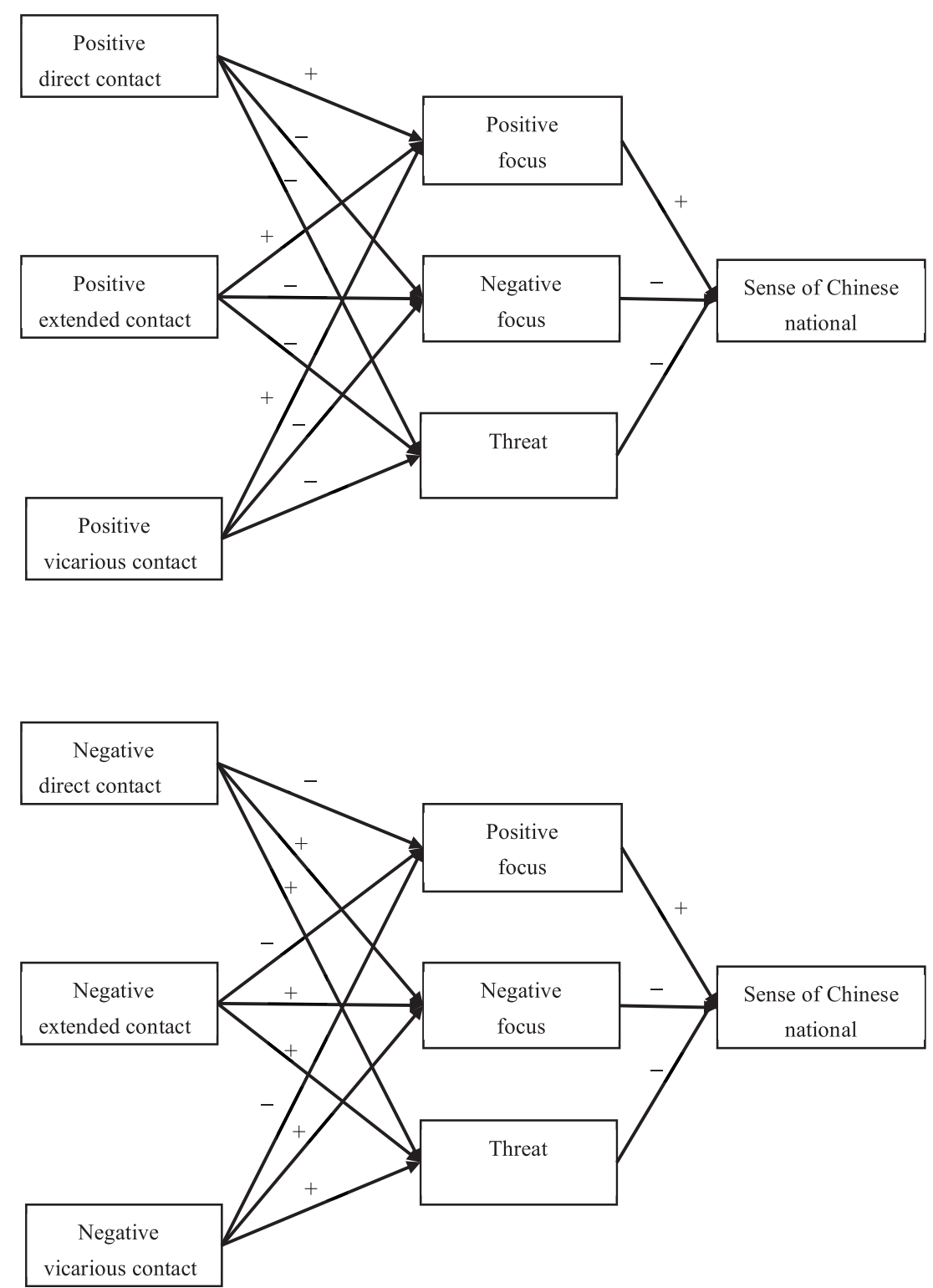

Fig. 1. Tested path model (for descriptive purposes, hypotheses for positive contact are presented separately from hypotheses for negative contact).

context of Han-Uyghur by Wang et al. (2019). We also created 4 positive and for negative ad hoc items for vicarious contact in order to match the other contact types.

For all items, we used a 5-point Likert-type response scale, which ranged from 1 (never) to 5 (very often), with higher scores reflecting more positive and negative contact, respectively. The Cronbach's $\alpha$ 's of the six scales for the majority and the minority sample are presented in Table 1.

\section{Positive and negative focus}

We created four items to assess focus, two for positive and two for negative focus. The response scale ranged from 1 (not at all) to 7 (extremely).

\section{Threat}

Eight items were adapted from Riek, Mania, Gaertner, McDonald and Lamoreaux (2010) to measure perceived intergroup threat between the two ethnic groups. Participants completed items assessing their perceptions on a 10-point scale, ranging from $1=$ strongly disagree to 10 = strongly agree. 


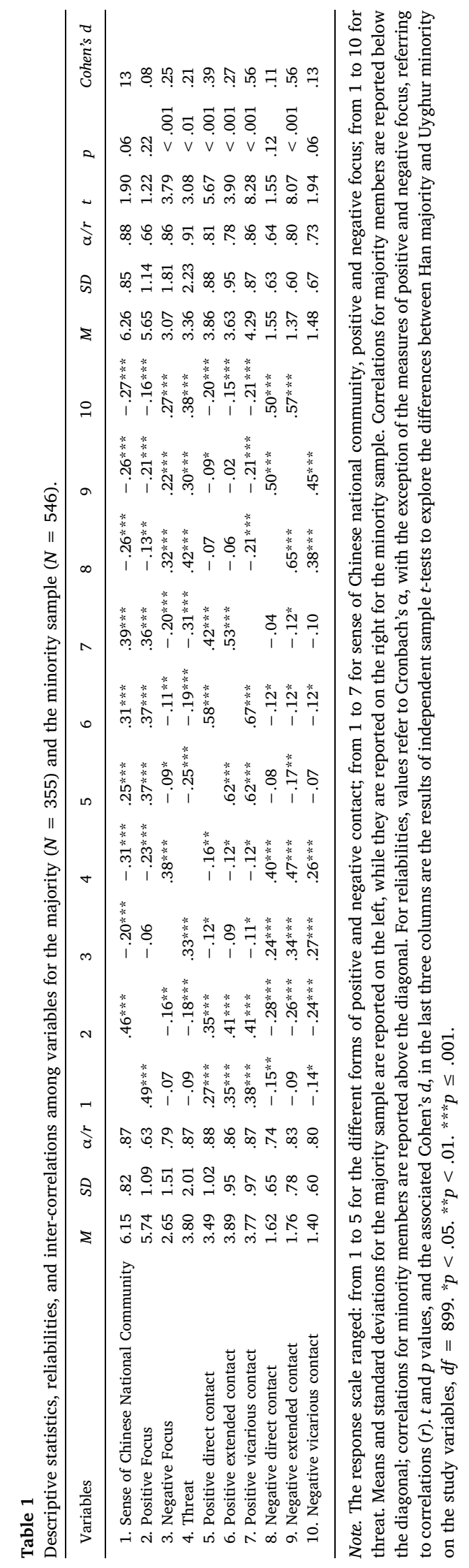




\section{Sense of Chinese national community}

The brief measure of sense of community (Peterson et al., 2008) was adapted to the Chinese national context, and we refer to it as sense of Chinese national community. The scale consisted of 8 items designed to assess four dimensions: needs fulfillment (e.g., "I can get what I need in the big family of Chinese nation"), group membership (e.g., "I feel like a member of the big family of Chinese nation"), influence (e.g., "I have a say on things related to the big family of Chinese nation"), and emotional connection (e.g., "I feel connected to the big family of Chinese nation"). The response scale ranged from 1 (strongly disagree) to 7 (strongly agree). ${ }^{1}$

\section{Results}

\section{Preliminary analyses}

Descriptive statistics and inter-correlations among variables are reported in Table 1. We conducted a series of independent sample $t$-tests to explore the differences between Han majority and Uyghur minority participants on the study variables. Results are shown in Table 1. No significant differences between groups emerged for sense of Chinese national community or for positive focus. Minority members reported greater negative focus and perceived less threat than the majority. Regarding the three types of contact, minority members reported greater positive direct contact, positive and negative vicarious contact than the majority, whereas no significant difference emerged for negative direct contact; positive and negative extended contact were higher among majority than minority members. In line with previous research (Barlow, Sibley, \& Hornsey, 2012; Graf, Paolini, \& Rubin, 2014; Visintin et al., 2017), for both groups, all positive forms of contact were more frequent than negative contact forms, $t s>28.22$, ps $<.001$, Cohen's $d s>1.50$.

\section{Path analysis}

We tested the path model with all forms of positive and negative contact included simultaneously (see Fig. 1). Specifically, we conducted a path analysis with observed variables with LISREL 8.7 (Jöreskog \& Sörbom, 2004). All possible paths were estimated, resulting in perfect fit. Results are presented in Table 2.

As can be seen, for the majority sample, positive extended and vicarious contact were associated positively with positive focus; negative direct and vicarious contact were associated negatively with positive focus. In addition, negative extended and vicarious contact were positively associated with negative focus; negative direct and extended contact were positively associated with threat. In turn, only positive focus was (positively) associated with sense of Chinese national community.

For the minority sample, the three forms of positive contact were positively associated with positive focus; negative extended contact was negatively associated with positive focus; positive vicarious contact, and negative direct and vicarious contact were associated with (negatively and positively, respectively) negative focus; positive direct and vicarious contact were negatively associated with threat, whereas the associations between negative direct and vicarious contact and threat were positive.

Indirect effects were tested using a bootstrapping method (Preacher \& Hayes, 2008) with 5000 bootstrap samples are presented in Tables 3 and 4. As can be seen in the table, for both groups, only positive focus emerged as a significant mediator. For the majority group, positive extended and vicarious contact were indirectly associated with greater sense of Chinese national community via increased positive focus; in addition, negative direct contact was indirectly associated with lower sense of Chinese national community via a reduction in positive focus. For the minority group, the three forms of positive contact were indirectly associated with higher sense of Chinese national community via greater positive focus; negative extended contact was indirectly associated with lower sense of Chinese national community via a reduction in positive focus.

In order to test whether effects differed based on group membership, we conducted a multiple group analysis with group (majority vs. minority) as the moderator. We first tested a model in which parameters were allowed to be freely estimated across samples. We then tested a model where equality constraints were applied to the path coefficients one at a time. A chi-square difference test was used to compare these nested models. To simplify the results, non-significant paths were removed from the model. The results of the final equivalence model are presented in Table 2 . The model provided adequate fit to the data, $\chi^{2}(55)=32.57, p=.993 ; \chi^{2} / d f=$ .59 ; SRMR $=.02$; RMSEA $=.00$; CFI $=1.00$.

As can be seen in Table 2, amongst the positive contact forms, only positive vicarious contact differed between groups, with the negative association with threat being significant only for the minority group. In contrast, we found several differences between groups for negative forms of contact: the negative associations of negative direct and vicarious contact with positive focus, and the positive association of negative extended contact with negative focus and threat, were significant only for the majority group; the positive associations of negative direct contact with negative focus and of negative vicarious contact with threat, and the negative associations of positive vicarious contact with threat and of negative extended contact with positive focus were significant only for the minority group.

\section{Discussion}

In this study we provided the first comparative test of three forms of contact (direct, extended, and vicarious) vis-à-vis sense of Chinese national community in a conflictual context, by considering both majority and minority members' perspectives. We collected

\footnotetext{
${ }^{1}$ All data, analytic methods, and study materials available upon request to the first author.
} 


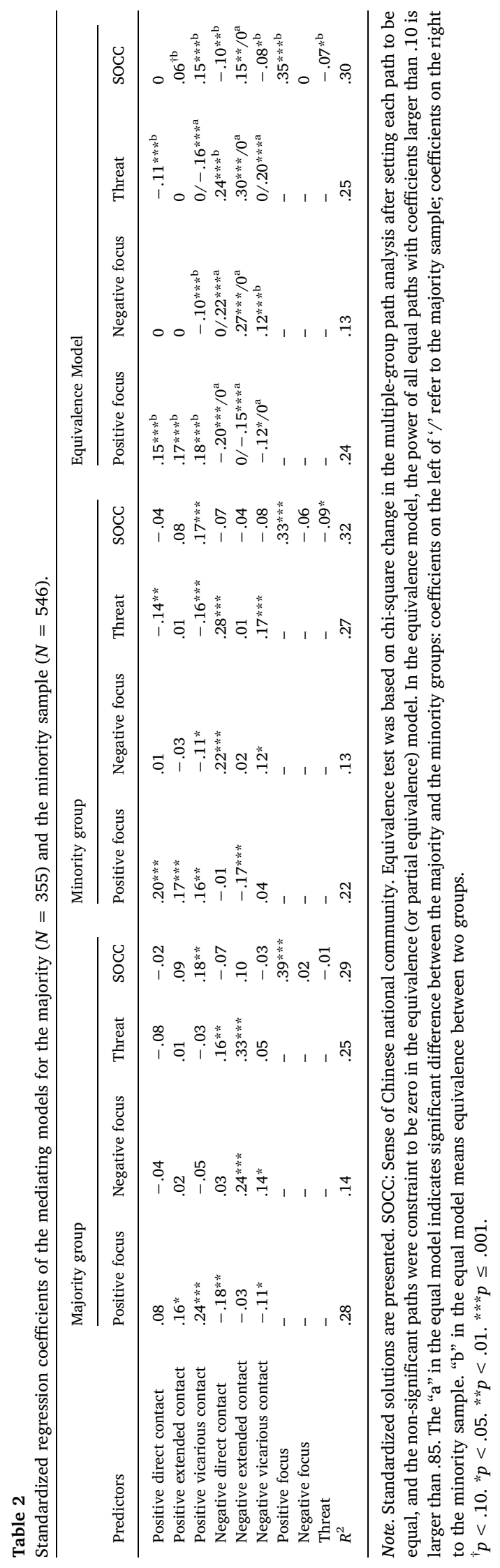


Table 3

Indirect effects for the majority sample $(N=355)$.

\begin{tabular}{|c|c|c|c|c|}
\hline Predictor & Mediator & $M$ & $S E$ & $95 \% \mathrm{CI}$ \\
\hline Positive direct contact & Positive focus & .029 & .0239 & {$[-.0169, .0780]$} \\
\hline Positive extended contact & Positive focus & .061 & .0280 & {$[.0280, .1180]$} \\
\hline Positive vicarious contact & Positive focus & .093 & .0334 & {$[.0346, .1634]$} \\
\hline Negative direct contact & Positive focus & -.072 & .0276 & {$[-.1301,-.0225]$} \\
\hline Negative extended contact & Positive focus & -.012 & .0293 & {$[-.0689, .0456]$} \\
\hline Negative vicarious contact & Positive focus & -.043 & .0254 & {$[-.0973, .0023]$} \\
\hline Positive direct contact & Negative focus & -.001 & .0040 & {$[-.0101, .0070]$} \\
\hline Positive extended contact & Negative focus & .000 & .0034 & {$[-.0077, .0075]$} \\
\hline Positive vicarious contact & Negative focus & -.001 & .0043 & {$[-.0102, .0079]$} \\
\hline Negative direct contact & Negative focus & .001 & .0038 & {$[-.0071, .0096]$} \\
\hline Negative extended contact & Negative focus & .004 & .0124 & {$[-.0205, .0309]$} \\
\hline Negative vicarious contact & Negative focus & .002 & .0078 & {$[-.0142, .0193]$} \\
\hline Positive direct contact & Threat & .001 & .0059 & {$[-.0117, .0144]$} \\
\hline Positive extended contact & Threat & -.000 & .0038 & {$[-.0089, .0075]$} \\
\hline Positive vicarious contact & Threat & .000 & .0042 & {$[-.0087, .0092]$} \\
\hline Negative direct contact & Threat & -.002 & .0100 & {$[-.0238, .0170]$} \\
\hline Negative extended contact & Threat & -.002 & .0190 & {$[-.0385, .0382]$} \\
\hline Negative vicarious contact & Threat & -.000 & .0048 & {$[-.0108, .0103]$} \\
\hline
\end{tabular}

Note. Means, SEs and $95 \%$ CIs were based on 5000 bootstrap samples.

Table 4

Indirect effects for the minority sample $(N=546)$.

\begin{tabular}{|c|c|c|c|c|}
\hline Predictor & Mediator & $M$ & $S E$ & $95 \% \mathrm{CI}$ \\
\hline Positive direct contact & Positive focus & .064 & .0179 & {$[.0308, .1022]$} \\
\hline Positive extended contact & Positive focus & .055 & .0212 & {$[.0173, .0999]$} \\
\hline Positive vicarious contact & Positive focus & .055 & .0190 & {$[.0194, .0947]$} \\
\hline Negative direct contact & Positive focus & -.002 & .0174 & {$[-.0352, .0326]$} \\
\hline Negative extended contact & Positive focus & -.056 & .0201 & {$[-.0976,-.0194]$} \\
\hline Negative vicarious contact & Positive focus & .012 & .0174 & {$[-.0215, .0475]$} \\
\hline Positive direct contact & Negative focus & -.001 & .0037 & {$[-.0088, .0065]$} \\
\hline Positive extended contact & Negative focus & .002 & .0042 & {$[-.0056, .0118]$} \\
\hline Positive vicarious contact & Negative focus & .007 & .0056 & {$[-.0022, .0197]$} \\
\hline Negative direct contact & Negative focus & -.013 & .0097 & {$[-.0346, .0043]$} \\
\hline Negative extended contact & Negative focus & -.001 & .0037 & {$[-.0104, .0056]$} \\
\hline Negative vicarious contact & Negative focus & -.007 & .0060 & {$[-.0214, .0023]$} \\
\hline Positive direct contact & Threat & .013 & .0093 & {$[-.0007, .0350]$} \\
\hline Positive extended contact & Threat & -.001 & .0056 & {$[-.0132, .0101]$} \\
\hline Positive vicarious contact & Threat & .015 & .0090 & {$[-.0005, .0349]$} \\
\hline Negative direct contact & Threat & -.026 & .0151 & {$[-.0591, .0010]$} \\
\hline Negative extended contact & Threat & -.001 & .0055 & {$[-.0126, .0104]$} \\
\hline Negative vicarious contact & Threat & -.016 & .0103 & {$[-.0388, .0006]$} \\
\hline
\end{tabular}

Note. Means, SEs and 95 \% CIs were based on 5000 bootstrap samples.

data from a specific interethnic context in China, providing external validity to the larger contact literature (Henrich, Heine, \& Norenzayan, 2010).

At a descriptive level, it is worth noting that both Han and Uyghur people reported a high level of sense of Chinese national community, with no differences between groups. This finding underlies the relevance of this construct in the context examined, indicating that local and national policies concerning ethnic and interethnic relations appear to be successful. These considerations are also supported by the relatively low level of threat in both groups. It is, however, worth noting that threat was slightly higher in the majority compared with the minority group. A potential reason lies in the actual or perceived threat that potential terrorist attacks generated among the majority group.

Concerning mediators, only positive focus emerged as a significant underlying process. Specifically, positive contact (extended and vicarious for both majority and minority; direct, for the minority) were associated with greater focus on the positive characteristics of outgroup members, and in turn with greater sense of Chinese national community. It is worth noting that positive focus also mediated the effect of negative contact (direct for the majority, extended for the minority), such that negative contact was associated with a reduced tendency to focus on the positive characteristics of the outgroup, and in turn with lower sense of Chinese national community. Possibly, with the focus on negative characteristics when dealing with rival outgroups (Shelton et al., 2006), contact drives the focus of attention to positive (counter-stereotypical) characteristics (increasing it when it is positive, or reducing it when it is negative), with consequences on the level of sense of community. Indirect support for this contention is provided by Zingara, Graf and Vezzali (2019), who found in a longitudinal study that majority (Czech) participants' contact with minority groups 
(Vietnamese, Roma) in the Czech Republic was most effective when such contact provided counter-stereotypical information. Our findings go a step further, showing that contact can foster or limit (depending on contact valence) the search for positive characteristics (as shown by associations between contact and positive focus, the main mediator emerged). Interestingly, these findings emerged for both positive forms of indirect contact among the majority group members, supporting the beneficial effect of indirect contact (Vezzali et al., 2014). Although all tested mediators were associated with sense of Chinese national community among both groups (cf. Table 1), we did not find indirect effects via negative focus or intergroup threat. These findings further underscore the importance of considering a range of variables relevant to the context, in order to partial out effects and allow for the emergence of the most relevant variables.

Concerning differences between positive and negative contact forms, our findings generally suggested effects for both. Based on these results, we cannot state that positive contact has stronger effects than negative contact, or vice versa. Instead, we can conclude that positive and negative forms of contact may complement one another.

We also investigated differences between groups. For the majority of paths, results were equivalent across groups. Differences emerged primarily concerned negative contact forms. It is, however, difficult to identify a clear pattern, because both direct and indirect contact had effects for both groups. We argue, however, that, despite this complexity, these differences highlight a similarity between groups, namely that positive and negative contact forms exerted effects for both groups.

These findings suggest a complex picture of the effects of positive and negative direct and indirect contact. This pattern is in line with Pettigrew and Hewstone's (2017) argument that we need to include several variables that may be relevant to a particular outcome, so as to obtain unbiased results. In addition, our findings reflect the importance of considering contact as a general strategy: if the aim is to foster community cohesion, then all relevant, direct and indirect contact forms should be considered simultaneously in order to understand which form is the most effective in a particular context. Such analysis should also consider the detrimental counter-effects of negative contact; otherwise we risk basing interventions on overly optimistic expectations stemming from research on positive contact.

It is worth noting that, in the present study, we examined additive effects of positive and negative contact. At least in some cases, positive and negative may interact with one another (Árnadóttir et al., 2018; but see Ten Berge, Lancee, \& Jaspers, 2017). Although our study was not designed to test interactions (given the high number of types of contact tested), future studies should consider their interplay in order to provide a more comprehensive picture of the effects of positive and negative direct and indirect contact.

\section{Community-diversity dialectic}

One of the core ideas of Confucianism is harmony but not uniformity. This principle influences interpersonal and intergroup relations, as well as official policies of China, including ethnic and interethnic domains. There are 56 ethnic groups in China, including the Han majority and 55 minority groups. In the Chinese official narrative, these ethnic groups are provided with equal status as members of a big family, the Chinese nation. Using the concepts of community psychology, each ethnic group is a small community, and the Chinese nation is the larger community that encompasses all units. The sense of Chinese national community does not imply dropping the different ethnic identities. Rather, it relates to the common ground allowing differences to exist and be expressed, helping one another to progress together. This sense of the larger community implies more responsibility for attributing value to each individual community, thereby lowering tensions between individual subcommunities (Townley et al., 2011).

Communities can be complex and hierarchical structures. For example, Uyghur people can be Kashi Uyghur, Uyghur of Southern Xinjiang, Uyghur of Xinjiang, or Uyghur Chinese, with each higher-order category inclusive of the lower-order category, but operating interdependently and influencing individual and larger community outcomes (Brodsky et al., 2002). Mannarini, Talò and Rochira (2017) found that the level of community diversity moderated the effect of sense of community, in some cases leading to increased prejudice with high levels of diversity and, presumably, high threat generated by this diversity. Clearly, what is crucial is how this diversity is appraised and valued at the level of the community. This consideration is consistent with the framework proposed by Kelly, Azelton, Burzette and Mock (1994), where diversity originated from the social setting in which people value, embrace and "use" differences for the benefit of the collective. We believe this is the case investigated in the present study.

\section{Implications and limitations}

We believe that this study has several strengths. First, it advances research on the psychological mechanisms of positive and negative contact by examining the mediating role of positive focus. Second, the present study provides evidence for intergroup contact theory from the interethnic context of China by considering both Han majority and Uyghur minority individuals, while taking into account concurrent effects of positive and negative contact, and several direct and indirect contact forms. Third, our research extends contact theory to include sense of community, which is a broader concept than one-group identity (Gaertner \& Dovidio, 2000); sense of community is a psychological construct denoting social cohesion beyond group distinctions.

Practically, we believe this study has several noteworthy implications. As suggested from the concept and measurement of sense of community (McMillan \& Chavis, 1986), enhancing the ability of a larger community to help each person independently of his/her ethnic group to fulfill their needs can strengthen emotional connections between group members and enhance sense of cohesion because of group differences, rather than "despite" these differences. Our results suggest that, in order to construct sense of Chinese national community, even when considering two large and quite different ethnic groups like Han and Uyghur, on one hand interventions should aim at increasing the occurrence of positive interethnic contact. This consideration is in line with the efforts of the central and local governments in Xinjiang. On the other hand, it is important to minimize the frequency of negative interethnic 
contact, as we have found evidence that negative contact (also at the level of the social network - extended contact) can have detrimental consequences for sense of community. The focus can be on (a) direct intergroup experiences such as face-to-face interaction in ethnically mixed classes, dormitories, and educational campuses, and (b) indirect contact strategies, allowing individuals to learn about the contact experiences of their ingroup members, both through storytelling, actual observation of positive intergroup relations, and broadcasting positive events involving different ethnic groups. Importantly, this needs to be done by focusing on positive outgroup characteristics. Chinese national community is not a static concept, but rather a dynamic and complex construction (Townley et al., 2011), and should be treated as a process shaped by intergroup contact. Consistently, in order to address the relations between ethnic minority and majority groups in China, the universities and the local government implement many policies enabling more positive contact to promote the harmony of interethnic relations.

Despite these meaningful findings, and their theoretical and practical contributions, we also acknowledge some limitations. First, the cross-sectional nature of the present study does not allow us to make causal claims. Second, although both majority and minority perspectives were considered, only university participants from border provinces were surveyed, preventing generalization of the findings to other interethnic contexts and other regions. Future studies should explore contact in multiethnic contexts characterized by several ethnic groups, and should survey community members as well as students. Third, future studies should adopt different operationalizations of sense of Chinese national community, in order to exclude any potential conceptual overlap that we may inadvertently have created with measures of national identification.

In conclusion, the present findings point on the necessity of considering positive and negative direct and indirect contact simultaneously, from the perspectives of both majority and minority groups. This dynamic interplay can enhance the design of effective strategies to foster sense of community, which we believe is an important outcome for scholars investigating intergroup relationships.

\section{Appendix A}

\section{Positive direct contact}

1. Outgroup people have actively greeted me

2. I have cooperated with outgroup people to complete something

3. I have participated in (or organized) school or social activities together with outgroup people

4. I have eaten delicious food or travelled along with outgroup people

\section{Negative direct contact}

1. Outgroup people responded indifferently to conversations that I had initiated

2. Outgroup people have insulted or threatened me

3. I have had trouble with outgroup people in learning activities or in daily life

4. Outgroup people and I have had divergent opinions on issues, including ethnic issues

Positive extended contact

1. I got to know that ingroup people had enjoyable conversations with outgroup people

2. I got to know that ingroup people enjoyed playing sports with outgroup people

3. Ingroup people told me that they had taken part in entertainment activities with outgroup people

4. Ingroup people told me that they had engaged in a mutual exchange of culture with outgroup people and they had both learned from each other

\section{Negative extended contact}

1. Ingroup people told me that it is not easy to get along with outgroup people

2. Ingroup people told me that they were once cheated/ripped off by outgroup people

3. I got to know that ingroup people had quarreled with outgroup people

4. I got to know that ingroup people had physical conflict with outgroup people

Positive vicarious contact

1. I have watched movies and TV shows that involved both ingroup and outgroup actors or actresses

2. I have watched videos showing ingroup and outgroup people chatting and laughing cheerfully

3. I have watched videos showing ingroup and outgroup people helping each other

4. I have seen propaganda information about ingroup and outgroup people getting along well with each other

Negative vicarious contact

1. I have seen pictures or watched videos showing outgroup people harassing or creating difficulties for ingroup people 
2. I have read news about ingroup people clashing with outgroup people over transactions

3. While online, I have come across instances of ingroup people and outgroup people disagreeing or quarrelling with each other over ethnic issues

4. I have read articles that describe the tense relations between ingroup people and outgroup people

Positive focus

1. I focus on the positive characteristics of outgroup people

2. It is easy for me to find the positive properties of outgroup people

Negative focus

1. I focus on the negative characteristics of [outgroup] people

2. It is easy for me to find the negative properties of [outgroup] people

Threat

1. Outgroup people have more economic rights than they deserve

2. Outgroup people receive too much financial investment on health care

3. Outgroup people receive too much financial support on education

4. The tax system favors outgroup people

5. Outgroup people don't understand the worldview of my ethnic group

6. Outgroup people have different family values from my ethnic group

7. Outgroup people don't value the traditional customs of my ethnic group

8. Outgroup people have different work values from my ethnic group

\section{Sense of Chinese National community}

1. I can get what I need in the big family of Chinese nation

2. The big family of Chinese nation helps me fulfill my needs

3. I feel like a member of the big family of Chinese nation

4. My body and mind belong in the big family of Chinese nation

5. I have a say on things related to the big family of Chinese nation

6. People in the big family of Chinese nation are good at influencing each other

7. I feel connected to the big family of Chinese nation

8. I have a good bond with other members in the big family of Chinese nation

\section{References}

Aberson, C. L. (2019). Indirect effects of threat on the contact-prejudice relationship: A meta-analysis. Social Psychology, 50, 105-126. https://doi.org/10.1027/18649335/a000364.

Alcock, C. L., Camic, P. M., Barker, C., Haridi, C., \& Raven, R. (2011). Intergenerational practice in the community: A focused ethnographic evaluation. Journal of Community \& Applied Social Psychology, 21, 419-432. https://doi.org/10.1002/casp.1084.

Allport, G. W. (1954). The nature of prejudice. New York, NY: Addison-Wesley.

Andrews, N. P., Yogeeswaran, K., Walker, M. J., \& Hewstone, M. (2018). Effect of valenced vicarious online contact on out-group prejudice and perceived out-group variability: A study of online poker. Journal of Applied Social Psychology, 48, 571-581. https://doi.org/10.1111/jasp.12548.

Andrighetto, L., Vezzali, L., Bergamini, G., Nadi, C., \& Giovannini, D. (2016). Inside the earthquake: Perceived disaster exposure and outgroup helping intentions among Italian and immigrant victims of the 2012 Italian earthquakes. Group Processes \& Intergroup Relations, 19, 753-768. https://doi.org/10.1177/ 1368430215591040.

Árnadóttir, K., Lolliot, S., Brown, R., \& Hewstone, M. (2018). Positive and negative intergroup contact: Interaction not asymmetry. European Journal of Social Psychology, 48, 784-800. https://doi.org/10.1002/ejsp.2365.

Bagci, S. C., \& Gungor, H. (2019). Associations between perceived positive and negative parental contact and adolescents' intergroup contact experiences. International Journal of Intercultural Relations, 69, 76-86. https://doi.org/10.1016/j.ijintrel.2019.01.002.

Bagci, S. C., \& Turnuklu, A. (2019). Intended, unintended, and unknown consequences of contact: The role of positive-negative contact on outgroup attitudes, collective action tendencies, and psychological well-being. Social Psychology, 50, 7-23. https://doi.org/10.1027/1864-9335/a000355.

Barlow, F. K., Paolini, S., Pedersen, A., Hornsey, M. J., Radke, H. R., Harwood, J., ... Sibley, C. G. (2012). The contact caveat: Negative contact predicts increased prejudice more than positive contact predicts reduced prejudice. Personality \& Social Psychology Bulletin, 38, 1629-1643. https://doi.org/10.1177/ 0146167212457953.

Barlow, F. K., Sibley, C. G., \& Hornsey, M. J. (2012). Rejection as a call to arms: Inter-racial hostility and support for political action as outcomes of race-based rejection in majority and minority groups. The British Journal of Social Psychology, 51, 167-177. https://doi.org/10.1111/j.2044-8309.2011.02040.x.

Binder, J., Zagefka, H., Brown, R., Funke, F., Kessler, T., \& Mummendey, A. (2009). Does contact reduce prejudice or does prejudice reduce contact? A longitudinal test of the contact hypothesis among majority and minority groups in three European countries. Journal of Personality and Social Psychology, 96, 843-856. https://doi. org/10.1037/a0013470.

Birtel, M. D., Vezzali, L., \& Stathi, S. (2018). Extended contact and affective factors: A review and suggestions for future research. Testing, Psychometrics, Methodology in Applied Psychology, 25, 213-238. https://doi.org/10.4473/TPM25.2.4.

Brodsky, A. E. (2009). Multiple psychological senses of community in Afghan context: Exploring commitment and sacrifice in an underground resistance community. American Journal of Community Psychology, 44(3-4), 176-187. https://doi.org/10.1007/s10464-009-9274-4.

Brodsky, A. E., \& Marx, C. M. (2001). Layers of identity: Multiple psychology sense of community within a community setting. Journal of Community Psychology, 29(2), $161-178$.

Brodsky, A. E., Loomis, C., \& Marx, C. M. (2002). Expanding the concept of PSOC. In A. T. Fisher, C. C. Sonn, \& B. J. Bishop (Eds.). Psychological sense of community: Research, applications and implications (pp. 319-334). New York: Kluwer/Plenum.

Brown, R., \& Hewstone, M. (2005). An integrative theory of intergroup contact. Advances in Experimental Social Psychology, 37, 255-343. https://doi.org/10.1016/ 
S0065-2601(05)37005-5.

Brown, R., \& Paterson, J. (2016). Indirect contact and prejudice reduction: Limits and possibilities. Current Opinions in Psychology, 11, 20-24. https://doi.org/10.1016/ j.copsyc.2016.03.005.

Brylka, A., Jasinskaja-Lahti, I., \& Mahonen, T. A. (2016). The majority influence on interminority attitudes: The secondary transfer effect of positive and negative contact. International Journal of Intercultural Relations, 50, 76-88. https://doi.org/10.1016/j.ijintrel.2015.12.007.

Cakal, H., Hewstone, M., Guler, M., \& Heath, A. (2016). Predicting support for collective action in the conflict between Turks and Kurds: Perceived threats as a mediator of intergroup contact and social identity. Group Processes \& Intergroup Relations, 19, 732-752. https://doi.org/10.1177/1368430216641303.

Capozza, D., Trifiletti, E., Vezzali, L., \& Favara, I. (2013). Can contact improve humanity attributions? International Journal of Psychology, 48, 527-541. https://doi.org/ $10.1080 / 00207594.2012 .688132$.

Castelli, L., De Dea, C., \& Nesdale, D. (2008). Learning social attitudes: Children's sensitivity to the nonverbal behaviors of adult models during interracial interactions. Personality \& Social Psychology Bulletin, 34, 1504-1513. https://doi.org/10.1177/0146167208322769.

Castellini, F., Colombo, M., Maffeis, D., \& Montali, L. (2011). Sense of community and interethnic relations: Comparing local communities carrying in ethnic heterogeneity. Journal of Community Psychology, 39, 663-677. https://doi.org/10.1002/jcop. 20459.

Dhont, K., \& Van Hiel, A. (2011). Direct contact and authoritarianism as moderators between extended contact and reduced prejudice: Lower threat and greater trust as mediators. Group Processes \& Intergroup Relations, 14, 223-237. https://doi.org/10.1177/1368430210391121.

Di Bernardo, G. A., Vezzali, L., Stathi, S., Cadamuro, A., \& Cortesi, L. (2017). Vicarious, extended and imagined intergroup contact: A review of interventions based on indirect contact strategies applied in educational settings. Testing, Psychometrics, Methodology in Applied Psychology, 24, 3-21. https://doi.org/10.4473/TPM24.1.1.

Dovidio, J. F., Eller, A., \& Hewstone, M. (2011). Improving intergroup relations through direct, extended and other forms of in direct contact. Group Processes \& Intergroup Relations, 14, 147-160. https://doi.org/10.1177/1368430210390555.

Dovidio, J., Gaertner, S. L., \& Saguy, T. (2009). Commonality and the complexity of "we": Social attitudes and social change. Personality and Social Psychology Review, 13, 3-20. https://doi.org/10.1177/1088868308326751.

Gaertner, S. L., \& Dovidio, J. F. (2000). Reducing intergroup bias: The common in group identity model. Philadelphia, PA: Psychology Press.

Gaertner, S. L., Rust, M., Dovidio, J. F., Bachman, B. A., \& Anastasio, P. A. (1994). The contact hypothesis: The role of a common ingroup identity on reducing intergroup bias. Small Group Research, 25, 224-249. https://doi.org/10.1177/1046496494252005.

Gao, C. H. (2019). Sense of Chinese nation community: Concept, implications, and strategies. Journal of Southwest Minzu University (Humanities and Social Science), 12 , $24-30$.

Graf, S., \& Paolini, S. (2017). Investigating positive and negative intergroup contact: Rectifying a long-standing literature bias. In S. Vezzali, \& S. Stathi (Eds.). Current issues in social psychology-Intergroup contact theory: Recent developments and future directions (pp. 8-30). New York, NY: Routledge.

Graf, S., Paolini, A. S., \& Rubin, M. (2014). Negative intergroup contact is more influential, but positive intergroup contact is more common: Assessing contact prominence and contact prevalence in five Central European countries. European Journal of Social Psychology, 44, 536-547. https://doi.org/10.1002/ejsp.2052.

Gu, H. X. (2010). Strategies on international cooperation against the "Three Forces”. Journal of Xinjiang Normal University (Social Science), 31, 33-42. https://doi.org/ 10.14100/j.cnki.65-1039/g4.2010.01.002.

Hayward, L. E., Tropp, L. R., Hornsey, M. J., \& Barlow, F. K. (2017). Toward a comprehensive understanding of intergroup contact: Descriptions and mediators of positive and negative contact among majority and minority groups. Personality \& Social Psychology Bulletin, 43, 347-364. https://doi.org/10.1177/ 0146167216685291.

Henrich, J., Heine, S. J., \& Norenzayan, A. (2010). Most people are not WEIRD. Nature, 466, 29. https://doi.org/10.1038/466029a.

Hodson, G., Crisp, R. J., Meleady, R., \& Earle, M. (2018). Intergroup contact as an agent of cognitive liberalization. Perspectives on Psychological Science, 13, 523-548. https://doi.org/10.1177/1745691617752324.

Huang, F., Wang, C., Shi, K., \& Halike, A. (2018). The construction and validation of multi-dimensional interethnic contact scale in Uyghur-Han interethnic context. Psychology, Techniques and Applications, 6, 291-309. https://doi.org/10.16842/j.cnki.issn2095-5588.2018.05005.

Husnu, S., Mertan, B., \& Cicek, O. (2016). Reducing Turkish Cypriots children's prejudice toward Greek Cypriots: Vicarious and extended intergroup contact through storytelling. Group Processes \& Intergroup Relations, 21, 178-192. https://doi.org/10.1177/1368430216656469.

Jöreskog, K. G., \& Sörbom, D. (2004). LISREL 8.7 for Windows [Computer software]. Lincolnwood, IL: Scientific.

Kelly, J. G., Azelton, K. L., Burzette, R. G., \& Mock, L. O. (1994). Creating social settings for diversity: An ecological thesis. In E. J. Trickett, R. J. Watts, \& D. Birman (Eds.). Human diversity: Perspectives on people in context. San Francisco: Jossey-Bass.

Lardier, D. T., Reid, R. J., \& Garcia-Reid, P. (2018). Validations of the brief sense of community scale among youth of color from an underserved urban community. Journal of Community Psychology, 46, 1062-1074. https://doi.org/10.1002/jcop.22091.

Mahonen, T. A., \& Jasinskaja-Lathi, I. (2016). Ramifications of positive and negative contact experiences among remigrants from Russia to Finland. Cultural Diversity \& Ethnic Minority Psychology, 22, 247-255. https://doi.org/10.1037/cdp0000059.

Mannarini, T., Talò, C., Mezzi, M., \& Procentese, F. (2018). Multiple senses of community and acculturation strategies among migrants. Journal of Community Psychology, 46, 7-22. https://doi.org/10.1002/jcop.21913.

Mannarini, T., Talò, C., \& Rochira, A. (2017). How diverse is this community? Sense of community, ethnic prejudice and perceived ethnic heterogeneity. Journal of Community and Applied Psychology, 27, 181-195. https://doi.org/10.1002/casp.2295.

Mazziotta, A., Rohmann, A., Wright, S. C., De Tezanos-Pinto, P., \& Lutterbach, S. (2015). (How) does positive and negative extended cross-group contact predict direct cross-group contact and intergroup attitudes? European Journal of Social Psychology, 45, 653-667. https://doi.org/10.1002/ejsp.2110.

McMillan, D. W., \& Chavis, D. M. (1986). Sense of community: A definition and theory. Journal of Community Psychology, 14, 6-23. https://doi.org/10.1002/15206629(198601)14:1<6::AID-JCOP2290140103>3.0.CO;2-I.

Meleady, R., Seger, C. R., \& Vermue, R. (2017). Examining the role of positive and negative intergroup contact and anti-immigrant prejudice in Brexit. The British Journal of Social Psychology, 56, 799-808. https://doi.org/10.1111/bjso.12203.

Neal, Z. P., \& Neal, J. W. (2014). The (In)compatibility of diversity and sense of community. American Journal of Community Psychology, 53, 1-12. https://doi.org/10. $1007 /$ s10464-013-9608-0.

Paolini, S., \& McIntyre, K. (2019). Bad is stronger than good for stigmatized, but not admired outgroups: Meta-analytical tests of intergroup valence asymmetry in individual-to-group generalization experiments. Personality and Social Psychology Review, 23, 3-47. https://doi.org/10.1177/1088868317753504.

Paolini, S., Harwood, J., \& Rubin, M. (2010). Negative intergroup contact makes group memberships salient: Explaining why intergroup conflict endures. Personality \& Social Psychology Bulletin, 36, 1723-1738. https://doi.org/10.1177/0146167210388667.

Peng, K., \& Nisbett, R. E. (1999). Culture, dialectics, and reasoning about contradiction. The American Psychologist, 54, 741-754. https://doi.org/10.1037/0003-066X. 54.9.741.

Peterson, N. A., Speer, P. W., \& McMillan, D. W. (2008). Validation of a brief sense of community scale: Confirmation of the principal theory of sense of community. Journal of Community Psychology, 36, 61-73. https://doi.org/10.1002/jcop.20217.

Pettigrew, T. F. (2016). In pursuit of three theories: Authoritarianism, relative deprivation, and intergroup contact. Annual Review of Psychology, 67, 1-21. https://doi. org/10.1146/annurev-psych-122414-033327.

Pettigrew, T. F., \& Hewstone, M. (2017). The single factor fallacy: Implications of missing critical variables from an analysis of intergroup contact theory. Social Issues and Policy Review, 11, 8-37. https://doi.org/10.1111/sipr.12026.

Pettigrew, T. F., \& Tropp, L. R. (2006). A meta-analytic test of intergroup contact theory. Journal of Personality and Social Psychology, 90, 751-783. https://doi.org/10. 1037/0022-3514.90.5.751.

Preacher, K. J., \& Hayes, A. F. (2008). Asymptotic and resampling strategies for assessing and comparing indirect effects in multiple mediator models. Behavior Research Methods, 40, 879-881. https://doi.org/10.3758/BRM.40.3.879.

Reimer, N. K., Becker, J. C., Benz, A., Christ, O., Dhont, K., Klocke, U., ... Hewstone, M. (2017). Intergroup contact and social change: Implications of negative and positive contact for collective action in advantaged and disadvantaged groups. Personality \& Social Psychology Bulletin, 43, 121-136. https://doi.org/10.1177/ 
0146167216676478

Riek, B. M., Mania, E. W., \& Gaertner, S. L. (2006). Intergroup threat and outgroup attitudes: A meta-analytic review. Personality and Social Psychology Review, 10, 336-353. https://doi.org/10.1207/s15327957pspr1004_4.

Riek, B. M., Mania, E. W., Gaertner, S. L., McDonald, S. A., \& Lamoreaux, M. J. (2010). Does a common identity reduce intergroup threat? Group Processes \& Intergroup Relations, 13, 403-423. https://doi.org/10.1177/1368430209346701.

Rupar, M., \& Graf, S. (2019). Different forms of intergroup contact with former adversary are linked to distinct reconciliatory acts through symbolic and realistic threat. Journal of Applied Social Psychology, 49, 63-74. https://doi.org/10.1111/jasp.12565.

Saguy, T., \& Chernyak-Hai, L. (2012). Intergroup contact can undermine disadvantaged group members' attributions to discrimination. Journal of Experimental Social Psychology, 48, 714-720. https://doi.org/10.1016/j.jesp.2012.01.003.

Sarason, S. B. (1974). The psychological sense of community: Perspectives for community psychology. San Francisco, CA: Jossey-Bass.

Sasaki, S. J., \& Vorauer, J. D. (2010). Contagious resource depletion and anxiety? Spreading effects of evaluative concern and impression formation in dyadic social interaction. Journal of Experimental Social Psychology, 46, 1011-1016. https://doi.org/10.1016/j.jesp.2010.07.003.

Shelton, J. N., Richeson, J. A., \& Vorauer, J. D. (2006). Threatened identities and interethnic interactions. In M. Hewstone, \& W. Stroebe (Vol. Eds.), European review of social psychology: Vol. 17, (pp. 321-358). New York, NY: Psychology Press.

Sonn, C. C., \& Fisher, A. (1998). Sense of community: Community resilient responses to oppression and change. Journal of Community Psychology, 26, 457-472. https:// doi.org/10.1002/(SICI)1520-6629(199809)26:5<457::AID-JCOP5 > 3.0.CO;2-O.

Stathi, S., Husnu, S., \& Pendleton, S. (2017). Intergroup contact and contact norms as predictors of postconflict forgiveness. Group Dynamics Theory Research and Practice, 21, 20-39. https://doi.org/10.1037/gdn0000060.

Stephan, W. G., \& Stephan, C. W. (2000). An integrated theory of prejudice. In S. Oskamp (Ed.). Reducing prejudice and discrimination (pp. 23-45). Mahwah, NJ: Erlbaum.

Stoeckel, F. (2016). Contact and community: The role of social interactions for a political identity. Political Psychology, 37, 431-442. https://doi.org/10.1111/pops. 12295.

Ten Berge, J. B., Lancee, B., \& Jaspers, E. (2017). Can interethnic friends buffer for the prejudice increasing effect of negative interethnic contact? A longitudinal study of adolescents in the Netherlands. European Sociological Review, 33, 423-435. https://doi.org/10.1093/esr/jcx045.

The State Council Information Office of the People's Republic of China (2019). Historical matters concerning Xinjiang. Beijing: People's Press.

Townley, G., Kloos, B., Green, E. P., \& Franco, M. M. (2011). Reconcilable differences? Human diversity, cultural relativity, and sense of community. American Journal of Community Psychology, 47, 69-85. https://doi.org/10.1007/s10461-010-9379-9.

Tropp, L. R., \& Pettigrew, T. F. (2005). Relationships between intergroup contact and prejudice among minority and majority status groups. Psychological Science, 16, 951-957. https://doi.org/10.1111/j.1467-9280.2005.01643.x.

Turner, J. C. (1999). Social identity and self-categorization. In N. Ellemers, R. Spears, \& B. Doosje (Eds.). Social identity. Context, commitment, content (pp. 6-34). Oxford, UK: Blackwell.

Turner, R. N., Hewstone, M., Voci, A., Paolini, S., \& Christ, O. (2007). Reducing prejudice via direct and extended cross-group friendship. European Review of Social Psychology, 18, 212-255. https://doi.org/10.1080/10463280701680297.

Vedder, P., Wenink, E., \& van Geel, M. (2016). Explaining negative outgroup attitudes between native Dutch and Muslim youth in the Netherlands using the integrated threat theory. International Journal of Intercultural Relations, 53, 54-64. https://doi.org/10.1016/j.ijintrel.2016.05.001.

Vedder, P., Wenink, E., \& van Geel, M. (2017). Intergroup contact and prejudice between Dutch majority and minority youth in the Netherlands. Cultural Diversity \& Ethnic Minority Psychology, 23, 477-485. https://doi.org/10.1037/cdp0000150.

Vezzali, L., \& Stathi, S. (2017). The extended contact hypothesis: State of the art and future developments. In L. Vezzali, \& S. Stathi (Eds.). Intergroup contact theory: Recent developments and future directions (pp. 114-130). Abingdon, UK: Routledge.

Vezzali, L., Andrighetto, L., Capozza, D., Di Bernardo, G. A., \& Saguy, T. (2017). Discussing differences between groups: The content of intergroup encounters and motivation for social change among members of advantaged groups. Journal of Theoretical Social Psychology, 1, 52-59. https://doi.org/10.1002/jts5.12.

Vezzali, L., Hewstone, M., Capozza, D., Giovannini, D., \& Wölfer, R. (2014). Improving intergroup relations with extended and vicarious forms of indirect contact. European Review of Social Psychology, 25, 314-389. https://doi.org/10.1080/10463283.2014.982948.

Visintin, E. P., Voci, A., Pagotto, L., \& Hewstone, M. (2017). Direct, extended, and mass-mediated contact with immigrants in Italy: The associations with emotions, prejudice, and humanity perceptions. Journal of Applied Social Psychology, 47, 175-194. https://doi.org/10.1111/jasp.12423.

Wang, C., Huang, F., Stathi, S., \& Vezzali, L. (2020). Positive and negative intergroup contact and willingness to engage in intergroup interactions among majority (Han) and minority (Uyghur) group members in China: The moderating role of social dominance of orientation. International Journal of Intercultural Relations, 75, 132-140. https://doi.org/10.1016/j.ijintrel.2018.09.002.

Wang, C., Huang, F., \& Vezzali, L. (2019). A test of positive and negative extended contact among a Chinese minority with perceived in group norms and intergroup anxiety as mediators. Journal of Applied Social Psychology, 49, 399-408. https://doi.org/10.1111/jasp.12532.

Wright, S. C., Aron, A., McLaughlin-Volpe, T., \& Ropp, S. A. (1997). The extended contact effect: Knowledge of cross-group friendships and prejudice. Journal of Personality and Social Psychology, 73, 73-90. https://doi.org/10.1037/0022-3514.73.1.73.

Xi, J. P. (2018). Building a human community with a shared future. Beijing: Central Party Literature Press.

Zhou, S., Page-Gould, E., Aron, A., Moyer, A., \& Hewstone, M. (2018). The extended contact hypothesis: A meta-analysis on 20 years of research. Personality and Social Psychology Review, 23, 132-160. https://doi.org/10.1177/1088868318762647.

Zingara, T., Graf, S., \& Vezzali, L. (2019). Stereotypes in the face of reality: The effect of negative contact, contact consistent and inconsistent with stereotype on prejudice. Under review. 